\title{
In-vitro comparision of cytotoxicity and anti-microbial activity of three pulpectomy medicaments- Zinc oxide euginol,Metapex and Chitra HAP - Fill
}

\author{
Dr.Jeeva.P.P, Dr,N,Retnakumari \\ Assistant professor, Government Dental college kottayam.MDS,M.Phil, \\ Professor and Head of Pedodontics, Government Dental college kozhikode
}

\begin{abstract}
Various pulpectomy medicaments have been used in primary endodontics like Zinc oxide euginol, Calcium hydroxide, iodoform and their combinations. But due to disadvantages like toxicity, reduced antimicrobial activity, over retention or easy resorption, the currently used / commercially available materials do not satisfy all the requirements of an ideal pulpectomy medicament. Current trend in dentistry is towards the use of biomaterials like hydroxy apatite.So a hydroxy apatite based pulpectomy medicament "Chitra HAP - Fil" is compared with Zinc oxide euginol, Metapex to evaluate cytotoxicity and antimicrobial activity by in-vitro methods. Cytotoxicity was compared by direct contact method and confirmed by MTT assay. Antimicrobial activity is tested by agar diffusion method. The results of this study showed that Chitra HAP-Fil performed reasonably acceptable level of cytotoxicity and antimicrobial activity compared to other two materials.
\end{abstract}

Key words: Pulpectomy, Zinc oxide euginol, Metapex ,Chitra HAP - Fill, cytotoxicity and anti microbial activity.

\section{Introduction}

Developmental, anatomic and physiologic differences between primary and permanent teeth call for differences in the criteria for pulpectomy medicaments. An ideal pulpectomy material must possess the properties of being antibacterial, resorbable, harmless to periapical tissues and the developing tooth bud. In addition, it must easily fill the canals, adhere to the walls, not shrink and easily removable if necessary, radiopaque and cause no discoloration of teeth ${ }^{[1]}$.

Since the 1930s, Zinc Oxide Eugenol has been the material of choice as a pulpectomy medicament. But owing to its disadvantages like slow resorption, irritation to periapical tissues and alteration in the path of eruption of succedaneous tooth, it does not fulfil the requirements of an ideal pulpectomy medicament. ${ }^{[2,3]}$ Iodoform paste alone or in combination with Calcium Hydroxide is used as an alternative material (KRI paste, Maisto paste and Metapex), but all these get resorbed slightly faster than the primary roots. ${ }^{[3,4]}$ Calcium Hydroxide is not ideal for primary teeth endodontics because of its faster rate of resorption. ${ }^{[5]}$ Thus, it can be assumed that a combination of all these materials may not be ideal for pulpectomy.

Current trend in dentistry is towards the use of biomaterials like hydroxy apatite. In an attempt to find an appropriate root canal obturating material, Sree Chitra Tirunal Institute for Medical Sciences and Technology, Trivandrum, India designed a new product named "Chitra HAP-Fil". It is a hydroxyapatite nanoparticle gel based root filler material, which exactly corresponds to the mineral content of bone and dentine, deemed to be highly biocompatible. "Chitra HAP-Fil" apparently satisfies all requirements of an ideal pulpectomy material. This study was carried out to investigate the cellular and microbial response of "Chitra HAP-Fil in comparison with Zinc oxide Eugenol and Metapex by invitro methods.

Materials

\section{Materials and Methods}

The materials used for this study are Zinc oxide eugenol (ZOE), Metapex $\mathrm{Ca}(\mathrm{OH})_{2}$ and iodoform paste , Hydroxyapatite iodoform paste (Chitra HAP-Fil).(Figure 1)

\section{Hydroxy apatite - iodoform paste (Chitra HAP-Fil)}

The prime ingredient in the Chitra HAP-Fil paste is hydroxyapatite nanoparticle gel (65\%) which is the basic mineral content of human bone and teeth. The rest of the paste is commercially pure iodoform (32\%) which imparts antibacterial property to the paste. Considering the ratio of iodoform in the paste and the quantity of the paste used in a single patient, it is well below the level of toxicity. The gelling agent (alginate) - $3 \%$ (including $0.2 \%$ surfactant) binds with the calcium ions in the hydroxyapatite. The paste is toxicologically safe and provided premixed and filled in $1 \mathrm{ml}$ syringe, so that it can deliver into the canal using disposable tips. 


\section{Methods}

The major concern in designing a root canal filling material is the safety of pulpal and periapical tissues as well as that of the erupting bud of permanent teeth. For this, the cellular response and antimicrobial activity of the three pulpectomy medicaments (ZOE,Metapex and Chitra HAP - Fill) were compared by in-vitro methods

\section{Cellular response through direct contact method}

The method used for cellular response was the ISO approved protocol (ISO 10993-5, 1999) for direct contact test using L929 mouse fibroblast cells. The direct contact method generally requires sterile samples in solid disc form. As all the materials in the study are pastes, cell compatible plastic rings (inner diameter $4.5 \mathrm{~mm}$ ) were introduced to transfer the materials on to the cell layers. $100 \mu \mathrm{l}$ of $130 \mathrm{mg} \%$ phenol was used as positive control. Then the culture plate was incubated for $24 \mathrm{hrs}$ in $5 \% \mathrm{CO}_{2}-95 \%$ air mixture at $37^{\circ} \mathrm{C}$ in an incubator. After 24 hrs of incubation, the cells were observed under phase contrast inverted microscope to observe the cell morphology for qualitative evaluation. In order to make the observation quantitative, MTT assay was carried out.

MTT assay :- The MTT assay, first described by Mosmann ${ }^{[5]}$ in 1983 focuses in the capacity of mitochondrial dehydrogenase enzyme in living cells to convert the yellow water soluble tetrazolium salt 3,4(4,5-dimethyl thiazole-2-YL), 2,5-diphenyl tetrazolium bromide (MTT) into dark blue formazen crystals. These water insoluble crystals are stored in the cytoplasm of living test cells, as the cells are largely impermeable to them. The number of surviving cells is, thus directly proportional to the level of the formazen product formed. Solubilisation of the cells by the addition of a detergent results in the liberation of the crystals that are solubilized. The colour can then be quantified using a simple colorimetric assay using ELISA reader.

After $24 \mathrm{hrs}$ of incubation period, the contents are removed from the culture wells. Then $200 \mu \mathrm{l}$ of MTT, working solution ( $0.5 \mathrm{mg}$ of MTT per $\mathrm{ml}$ serum free media) was added to each well. The culture plates are incubated overnight in a humidified atmosphere at $37^{\circ} \mathrm{C}$.After this, MTT solution was removed from the culture plates and $200 \mathrm{ml}$ of propanol was added and plates were incubated at $37^{\circ} \mathrm{C}$ for $20 \mathrm{~min}$ in shaker incubator for solubilisation of crystals. Following this, spectrophetometric absorbance is measured at $570 \mathrm{~nm}$, with reagent under ELISA reader.

\section{Antibacterial activity testing}

Antibacterial property is tested by Agar Diffusion Method.

Agar Diffusion Method. Mueller-Hinton agar plates ${ }^{[6]}$ were used, approximately 25 to $30 \mathrm{ml}$ of the medium (pH 7.2 to 7.4 ) was poured onto a $9 \mathrm{~cm}$ diameter petridish stored at $2-8^{0} \mathrm{C}$. The bacterial inoculums of $\boldsymbol{E}$. faecalis (clinical isolate) and Staphylococcus aureus (ATCC 25923) were prepared. For standardization of the inoculum density McFarland 0.5 turbidity standard of barium sulfate prepared from barium chloride dehydrate and sulfuric acid was used.

Filter paper discs (4mm inner diameter) were used for sample transfer, as the samples were in paste form. The discs were placed on Muller-Hinton agar plates using sterile forceps, at a distance of at least $24 \mathrm{~mm}$ apart. The test samples were transferred on to this disc as a droplet, keeping the droplet size as uniform as possible.Zinc oxide eugenol was placed directly on agar plate, because of its stickness. Gentamycin $10 \mu \mathrm{g}$ disc ( $4 \mathrm{~mm}$ diameter) was kept in each plate as positive control for comparison. The plates were placed in a bacteriological incubator at $35 \pm 2.5^{\circ} \mathrm{C}$. Each material was tested separately in triplicates and zone of inhibition was noted.(Figures 2-7)

\section{Results}

The present study evaluated the cytotoxicity and antimicrobial activity of three pulpectomy materials, namely zinc oxide eugenol,Chitra HAP-Fil and metapex. The cellular response of three materials were evaluated by direct contact method and the percentage of the viable cells was calculated from optical density values, (Figures 8 - 10) using the formula.

Percentage of viable cells $=\quad \frac{\text { Optical density of test well }}{\text { Optical density of negative control }} \times 100$

The percentage of viable cells (MTT assay) was calculated for different materials ( Metapex-67\%, Chitra HAPFil-39\%, zinc oxide eugenol-14\%)(Graph 1) 


\section{Mean percentage of viable cells in different materials}

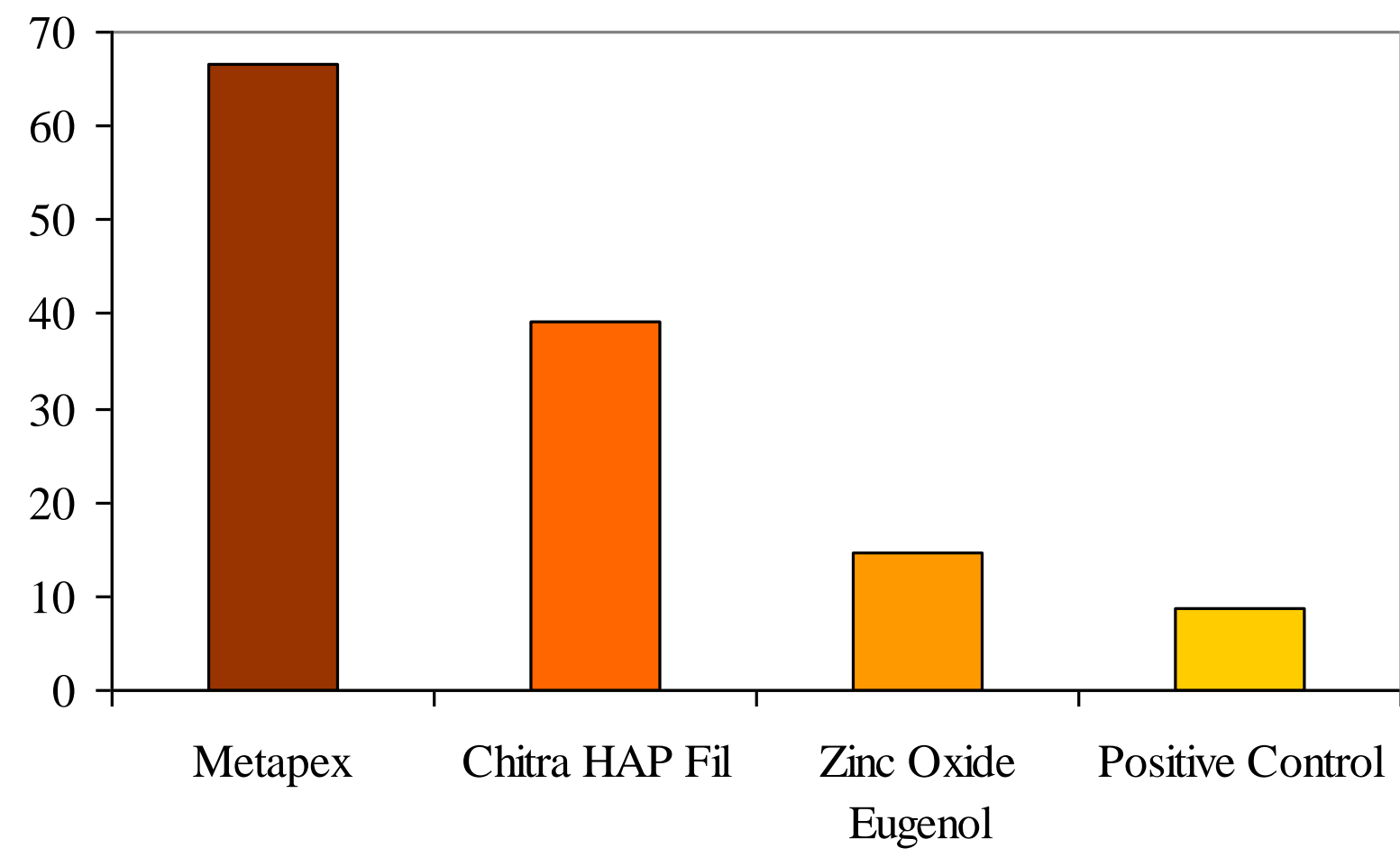

For comparing the cytotoxicity, statistical analysis was carried out by using parametric test, one - way ANOVA to know the statistical significant difference between the materials (Table 1). The difference in cytotoxicity of all three materials was highly significant $(\mathrm{P}<0.001)$. The results showed that Metapex is significantly least toxic than Chitra HAP-Fil which was less cytotoxic than ZOE.(Table 1)

Table 1 -Cytotoxicity of materials.

\begin{tabular}{|c|c|c|c|c|c|}
\hline Material & Mean & $\mathbf{\pm}$ SD & F value & p value & Significance \\
\hline Metapex & 66.532 & 1.120 & & \\
Chitra HAP-Fil & 39.343 & 0.888 & \multirow{2}{*}{4297.861} & \multirow{2}{*}{ Highly significant } \\
\cline { 1 - 3 } Zinc oxide eugenol & 14.738 & 0.721 & & \\
\hline Positive control & 8.790 & 0.148 & & \\
\hline
\end{tabular}

\section{Antibacterial activity test results}

Chitra HAP-Fil showed maximum antimicrobial activity against staphylococcus aureus. The zone of inhibition measured for Chitra HAP - Fil against S. aureus is $10 \mathrm{~mm}$. The zone of inhibition for zinc oxide eugenol is $7 \mathrm{~mm}$ and metapex showed no zone of inhibition against S. aureus. Zone of inhibition against enterococcus faecalis $(20 \mathrm{~mm})$ is seen with zinc oxide eugenol. There is no zone of inhibition against E. faecalis for chitra HAP - Fil and metapex.

\section{Discussion}

The most commonly used pulpectomy material is zinc oxide eugenol. It is known that ZOE alone or combination with a fixative can be used as pulpectomy material. It has got high success rate as suggested by Gould ${ }^{[7]}$ and Yacobi et al. ${ }^{[8]}$ Eugenol in particular has been reported to be cytotoxic and neurotoxic. Zinc Oxide was shown to be genotoxic, cytotoxic,able to kill macrophages and causing chronic and fibrous inflammatory reactions, ulcerations, and osteosclerosis. ${ }^{[2,3]}$ So ZOE, despite its wide usage, does not fulfill the requirements of an ideal root canal material. 
Iodoform alone or with calcium hydroxide and other materials (KRI paste, Maisto paste,Metapex and Vitapex) are widely used ${ }^{[3,4]}$ Calcium Hydroxide is may not ideal for primary endodontics, because of internal resorption. ${ }^{\text {[9] }}$ More over calcium hydroxide was shown to cause periapical inflammation, typical granuloma, and showed partial lack of healing. ${ }^{[10,11,12]}$ Calcium Hydroxide from the pulpecotmy material can also cause heterotopic calcifications in the body tissues. ${ }^{[13]}$ With regards to all these aspects, this combination of material may not ideal and safe.

Unfortunately none of the currently used or commercially available materials satisfied all the ideal criteria .The current trend in restorative dentistry is towards the use of biomaterials that are highly compatible with the surrounding tissues and closely resemble the physical, chemical and optical characteristics of dental tissues. The use of hydroxyapatite, a major component of all human hard tissues, would be the most logical answer to this quest. Hence, a new pulpectomy medicament which contain hydroxy apatite was formulated.

In the present study the cellular and microbial response of three pulpectomy materials were evaluated by invitro methods. Invitro method was selected because it has the advantages that all factors and variables can be controlled. For testing cellular response, the 'direct contact' method is used, i.e. the test materials were kept in direct contact with the cultured cell layer. This gives the immediate and true response, closer to the clinical conditions.

For antimicrobiological activity test, Agar Diffusion using the bacterial strains Enterococcus faecalis (clinical isolate) and Staphylococcus aureus (ATCC 25923)were used. E.faecalis was selected because it is a common primary endodontic pathogen and also seen in persistent endodontic infection. Its prevalence in such an infection ranges from $24 \%$ to $77 \%$. It can survive and grow within dentinal tubule and reinfect an obturated root canal. It is highly resistant in alkaline condition, such that of Calcium Hydroxide. Staphylococcus aures is a standard strain and it is commonly seen primary endodontic pathogen.

In this study the cytotoxicity of zinc oxide eugenol, Chitra HAP Fil and Metapex were compared. The results showed that the difference in cytotoxicity of all three materials are very highly significant. $(\mathrm{p}<0.001)$. The conclusion of results showed that Metapex is significantly least cytotoxic than Chitra HAP Fil which is less cytotoxic than zinc oxide eugenol. This is similar to other studies conducted by Pissiotis et al, Gulati and Chandra et al which suggested significant cytotoxicity of zinc oxide eugenol than other materials. ${ }^{[14,15]}$ In the case of Metapex, the calcium ions are coated with silicon oil which reduce its leaching out during direct contact method and this could be the reason for its least cytotoxicity. But the diffusion rate of an oily based medicament increases with time as suggested by Ajitha $\mathrm{P}$ et al. ${ }^{[16]}$ So on prolonged time periods it may exhibit more cytotoxicity. Considering the harmful effects of calcium hydroxide in Metapex even though it exhibited less cytotoxicity than Chitra HAP Fil, the later is considered to be a safe material for pulpectomy.

Metapex did not exhibit any antibacterial property by agar diffusion method against S.aures and E.faecalis . This finding is similar to that of the study conducted by Wen-Shin Chaou et al and Pabla et al. ${ }^{[17,18]}$ The antibacterial property of Chitra HAP Fil, was primarily against $S$. aureus and no anti-bacterial property was observed against E.faecalis. This was probably due to the fact that the E. faecalis used in the study was a clinically isolated strain, which may have possessed individual characteristics with regard to resistance and tolerance toward various chemical agents. Hence, it cannot be conclusively said that Chitra HAP-Fil would have no effect on any other strains of the same organism.With zinc oxide eugenol, antibacterial property was observed against both S.aures and E.faecalis by both methods. These finding were similar to that of White et al , Lai et al. ${ }^{[19,20]}$. This pronounced antimicrobial effect may be due to the intimate contact of the medicament with the pathogen in the various cell studies, which is less probable in the root canal system.

Cytotoxicity and antimicrobial activity are two such properties, which must be weighed on the opposite arms of a balance. Considering this norm, both Zinc oxide eugenol and Metapex fail to qualify as acceptable pulpectomy medicaments. Chitra HAP-Fil was seen to outshine both these materials against which it was evaluated, due to its reasonably acceptable levels of cytotoxicity as well as antimicrobial activity.

In Chitra HAP - Fil, the hydroxy apatite nano particle sizes are comparable with tooth crystals, so that the physiological resorption of the paste will be tuned to that of the roots of deciduous tooth. Because of its neutral $\mathrm{pH}$, makes it more compatable to the surrounding cells and tissues. American National Standard / American Dental Association(1988) specifies that a root canal filling material should be atleast $2 \mathrm{~mm}$ aluminium more radio opaque than dentin for optimal clinical application ${ }^{[21]}$. Chitra HAP-Fil satisfies this criteria as a pulpectomy material. The ingredients are harmless to the periapical tissues or to the developing tooth bud. It is easy to fill in the canals and provide good adherence to the canal walls and does not shrink after filling. It is shown to be chemically non reactive with the components of dentine and hence is not expected to cause any discoloration or degradation of teeth. The paste is not hard-setting and therefore the filling can be removed later if necessary. 


\section{Conclusion}

To conclude it needs to be highlighted that cytotoxicity and antimicrobial activity are two such properties, which must be weighed on the opposite arms of a balance. Considering this norm, both Zinc oxide eugenol and Metapex fail to qualify as acceptable pulpectomy medicaments. Chitra HAP-Fil is seen to outshine both these materials against which it was evaluated, as it has reasonably acceptable levels of cytotoxicity as well as antimicrobial activity.On analyzing all these factors, it is found that Chitra HAP-Fil apparently satisfies all the ideal requirements for a pulpectomy material.Thus Chitra HAP-Fil proves to be a promising ideal pulpectomy material. Further researches are required for evaluating the long term effectiveness and success of Chitra HAP-Fil as a pulpectomy material.

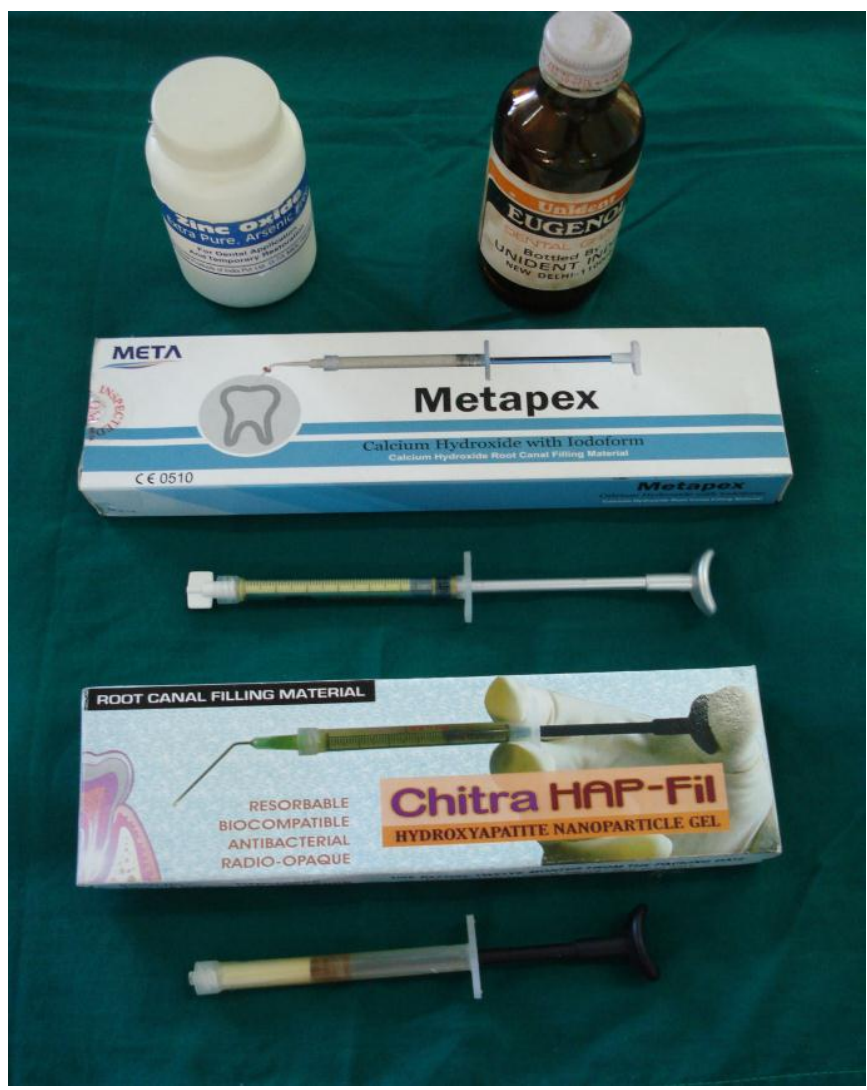

Fig - 1MATERIALS USED IN THE STUDY

\section{ANTIMICROBIAL ACTIVITY AGAINST ENTEROCOCCUS FAECALIS}

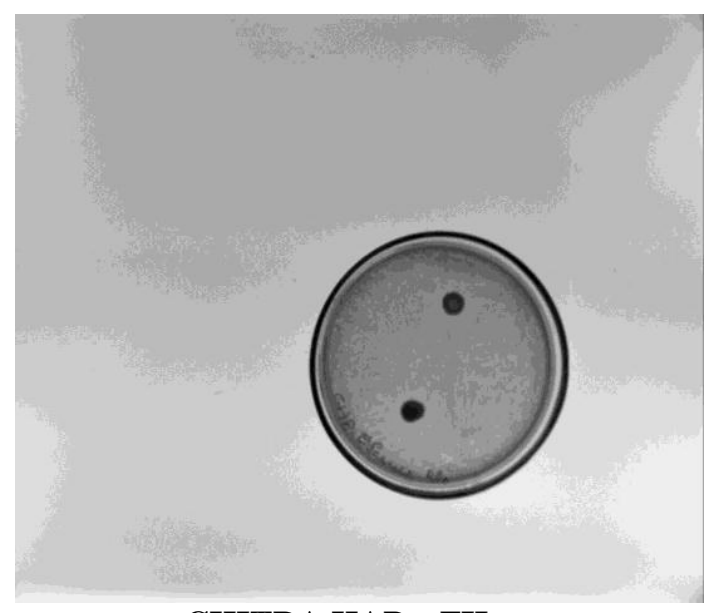

CHITRA HAP - FIL

Fig -2

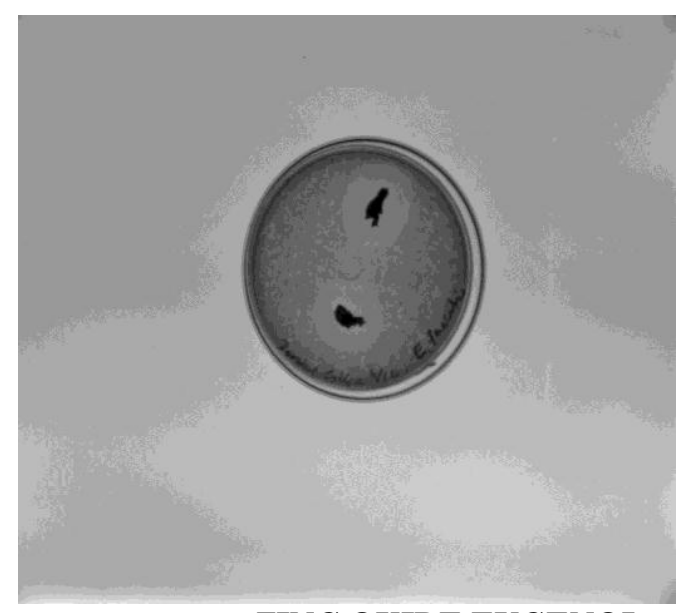

ZINC OXIDE EUGENOL

Fig -3 


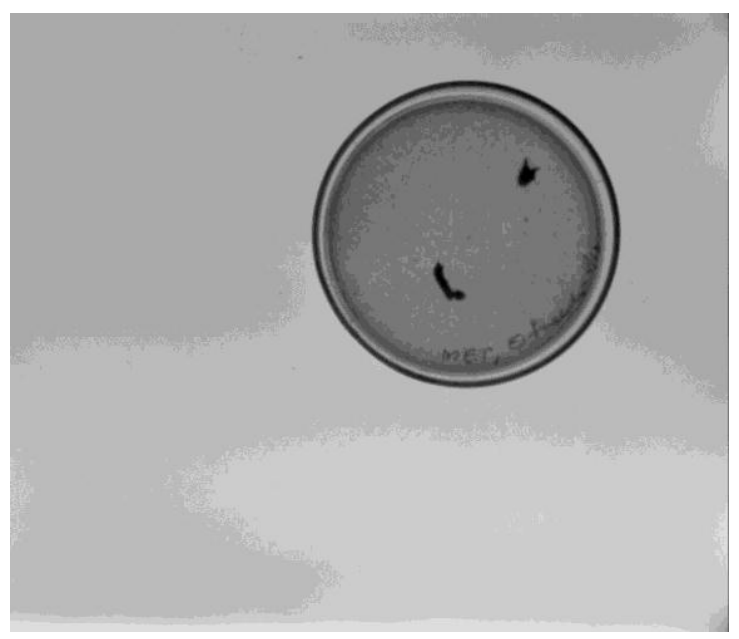

\section{METAPEX}

Fig - 4

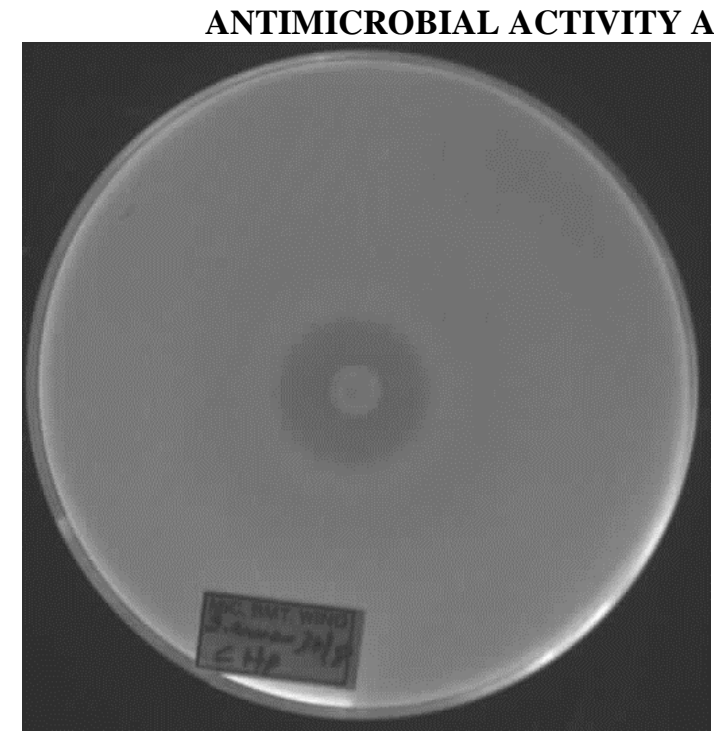

CHITRA HAP-FIL

Fig -5
STAPHYLOCOCCUS AUREUS

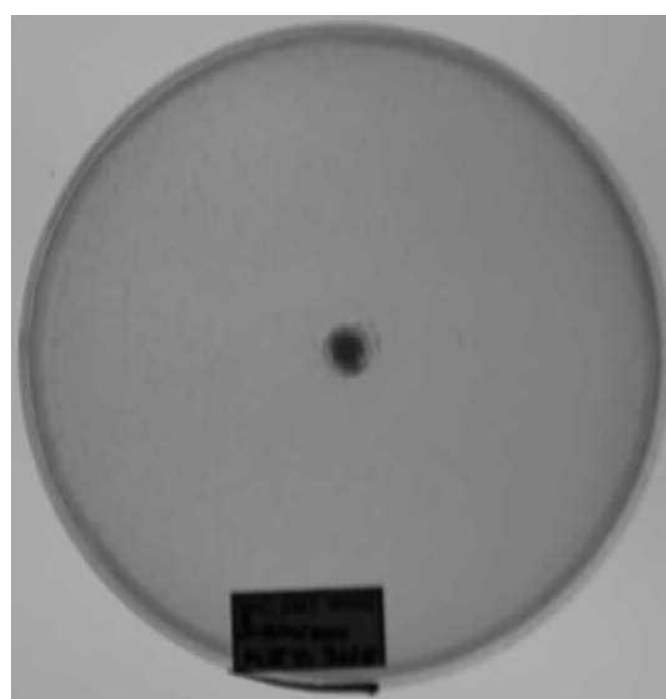

METAPEX

Fig - 6

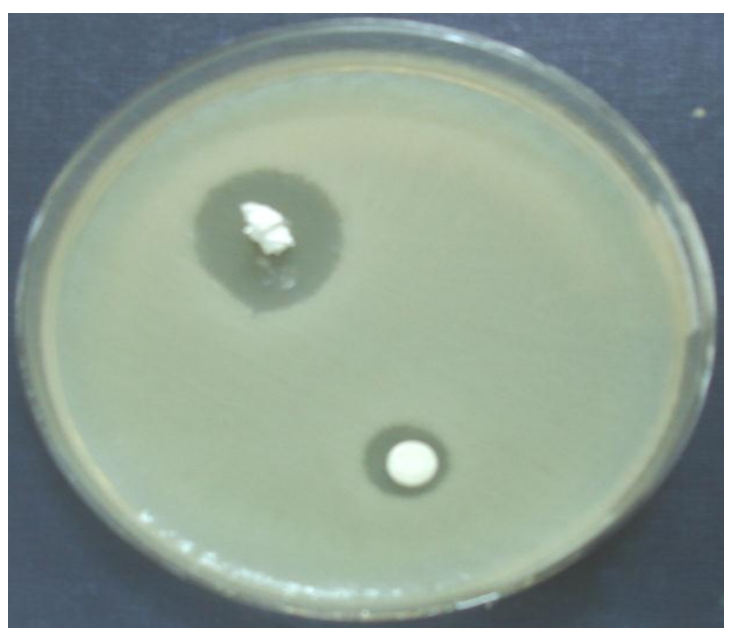

ZINC OXIDE EUGENOL

Fig- 7 


\section{PHOTOMICROGRAPHS SHOWING RESPONSE OF L929 MOUSE FIBROBLAST CELLS}

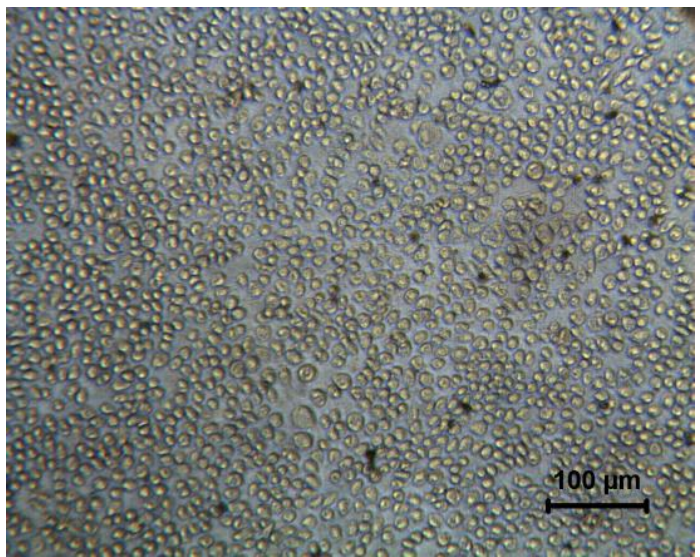

Fig -8

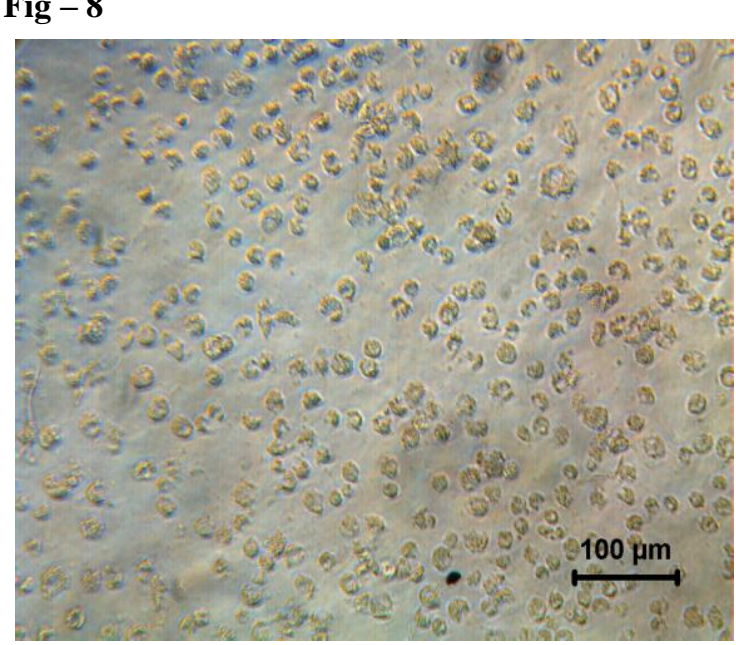

\section{ZINC OXIDE EUGENOL}

Fig - 10

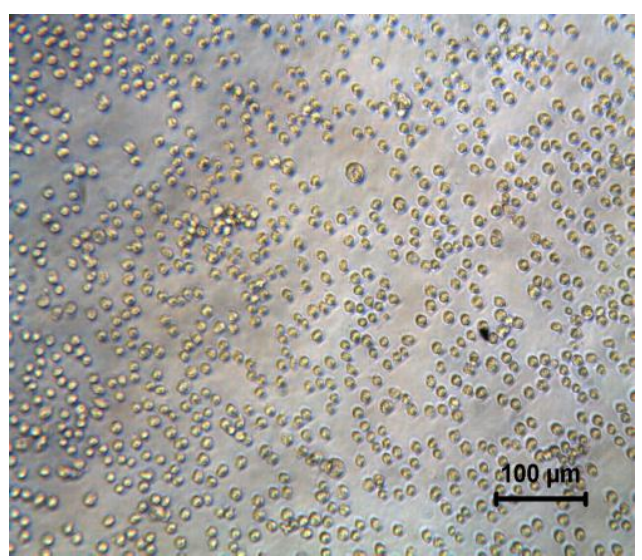

Fig - 9

\section{References}

[1]. Rifkin A. A. Simple, effective safe technique for the root canal treatment of abscessed primary teeth. J Dent Child 1980;17:435.

[2]. Erausquin J, Muruzabal M: Root canal fillings with zinc oxide eugenol in the rat molar. Oral Surg Oral Med Oral Path 1967;24:547-558.

[3]. Holan G, Fuks AB. A comparison of pupectomies using ZOE and KRI paste in primary molars: a retrospective study. Pediatr Dent. 1993; 15 (6): 403- 406.

[4]. Mass E, Zilberman UL. Endodontic treatment of infected primary teeth using Maisto's paste. ASDC J Dent Child 1989; 56(2): 117-20.

[5]. Mosmann T. Rapid calorimetric assay for cellular growth and survival, application to proliferation and cytotoxicity assay. J immunol methods $1983 ; 16,65(1-2) 55-63$.

[6]. Mueller J H\&Hinton Jane.A protein free medium for primary isolation of the Gonococcus and Meningiococcus. Proceedings of the society of experimental Biology \&Medicine 1941,$48 ; 33$.

[7]. Gould JM. Root canal therapy for infected primary molar teeth - preliminary report. J Dent Child 1972; $34: 23$.

[8]. Yacobi R et al. Evolving primary pulp therapy techniques. J Am Dent Assoc.1991;122:83.

[9]. Hendry JA, Jeansonne BG, Dummett CO,Burrell W. Comparison of calcium hydroxide and Zinc oxide eugenol pulpectomies in primary teeth of dogs. Oral Surg Oral Med Oral Pathol.1982, Oct; 54 (4) : 445-51.

[10]. Weinstein R, Goldman M; Apical hard tissue deposition in adult teeth of monkeys with the use of Calcium hydroxide.Oral Surg Oral Med Oral Pathol;1977, 43:627-630.

[11]. Beltes P, Koulaourzidou E, Kotoula V, Kortsaris AH: In vitro evaluation of the cytotoxicity of calcium hydroxide based root canal sealers. J Endod Traumat Oct.1995 11: 245.

[12]. Estrela C, Holland et al: Influence of iodoform on antimicrobial potential of calcium hydroxide. J Appli Oral Science.2006, 14(1):33-7.

[13]. Kawakami .T, C. Nakamura, S Eda. Effects of the penetration of a root canal filling material into the mandibular canal.Tissue reaction to the material. Endod \& Dent Traumat ; 7 ;); 36; Feb;1991.

[14]. Pissiotis E, Spanberg LS. Toxicity of Pulpispad using four different cell types. Int Endod J. 1991; 24 (5):249-57.

[15]. Gulati. N, S.Chandra, P.K.Aggarwal, J.N.Jaiswal, M. Singh. Cytotoxicity of eugenol in sealer containing Zinc oxide. Dent Traumat $1991 ;(7) ; 181-185$.

[16]. Ajitha P, Rao CVN, Lakshminarayanan L: Time dependent inhibitory effect of dentin on various Calcium hydroxide medicaments - An in vitro study. Endod 2003; 15. 
[17]. Wen-Shiun Tchaou, Been-Foo Turng, Glenn E. Minah, James A Coll. In vitro inhibition of bacteria from root canals of primary teeth by various dental materials. Pediat Dent 1995;17:5.

[18]. Pabla T,Gulati MS,Mohan U.Evaluation of antimicrobial efficacy of various root canal filling materials for primary teeth 1997;15 (4) 134-40.

[19]. White JM, Goodis H. In vitro evaluation of a Hydroxyapatite root canal system filling material. J Endod. 1991; 17(11):561-6.

[20]. Lai CC, Huang FM, Yang HW, Chan Y, Huang MS, Chou MY, Chang YC. Antimicrobial activity for four root canal sealers against endodontic pathogens. Clin Oral Investi 2001; 5(4):236-9.

[21]. Laghios CD, Benson BW, Gutmann JL, and Cutler CW. A comparative radiopacity of tetra calcium phosphate and other root canal filling materials. Int Endod j 2000; 33; 311-315. 